\title{
Synergic Effect of Clay on the Mechanical and Electrical Properties of SWCNT/Epoxy Composites
}

\author{
Won Seok Choi ${ }^{\#}$ and Sung Hun $\mathrm{Ryu}^{\dagger}$ \\ Department of Chemical Engineering, Kyung Hee University Yongin, Kyunggi-Do 446-701, South Korea \\ (Received July 7, 2014, Revised August 4, 2014, Accepted August 22, 2014)
}

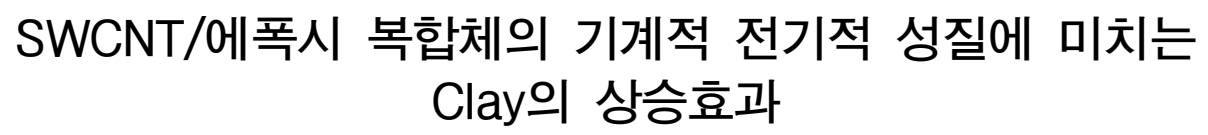

\author{
최원석\# · 류승훈 \\ 경희대학교 공과대학 화학공학과 \\ 접수일(2014년 7월 7일), 수정일(2014년 8월 4일), 게재확정일(2014년 8월 22일)
}

\begin{abstract}
Sodium-montmorillonite $\left(\mathrm{Na}^{+}-\mathrm{MMT}\right)$ was introduced into single wall carbon nanotube (SWCNT)/epoxy composite to investigate the effect of MMT size and MMT/SWCNT ratio on the mechanical and electrical properties of composite. Three different sizes of MMTs were used and all were found to function as effective dispersion aids for SWCNTs. Mechanical properties of SWCNT/epoxy composite increased with MMT content; tending to decrease once the MMT content reached a critical level. However, the surface electrical resistance decreased with increasing MMT content and tended to increase after the critical content was reached. Critical MMT/SWCNT ratio for maximum mechanical properties and minimum electrical resistivity was strongly dependent on the MMT size. Critical MMT/SWCNT ratio was decreased with MMT size.

요 약 : 단일벽 카본나노튜브 (SWCNT)/에폭시 복합체에 sodium-montmorillonite $\left(\mathrm{Na}^{+}-\mathrm{MMT}\right)$ 을 첨가하여 $\mathrm{MMT}$ 크기와 $\mathrm{MMT} / \mathrm{SWCNT}$ 비율이 복합체의 기계적 전기적 성질에 미치는 영향에 대하여 살펴보았다. 다른 크기를 갖는 3종류의 MMT를 사용하였으며, 모두 SWCNT의 분산에 효과적임을 알 수 있었다. MMT함량이 증가함에 따라 SWCNT/에폭시 복합체의 기계적인 성질은 증가하였으며, 임계함량에 도달한 후에는 감소하기 시작하였다. 그러나 표면전기저항은 $\mathrm{MMT}$ 함량이 증가함에 따라 감소하였으며, 임계함량에 도달한 후 증가하기 시작하였다. 최대 기계적 성질과 최소 전기특성은 임계 MMT/SWCNT 비율은 MMT 크기에 크게 의존하였으며, 이는 MMT크기가 증가함에 따라 감소하였다.
\end{abstract}

Keywords : single wall carbon nanotube, montmorillonite, MMT/SWCNT ratio, dispersion.

\section{I . Introduction}

The use of carbon nanotubes (CNTs) in polymer/CNT composites has attracted widespread attention because of the excellent intrinsic mechanical and electrical properties that are present at very high aspect ratios. CNTs have been used to reinforce various polymers, such as polystyrene, poly(methyl methacrylate), epoxy, and polypropylene. ${ }^{1-6}$

However, owing to strong van der Waals interactions, CNTs tend to agglomerate, which hinder the uniform dispersion of CNTs in polymer matrices and thereby complicate their use. To overcome this problem, various methods -- including the addition of surfactants or third components, as well as chemical functionalization -- have been used. Surfactants can help

\footnotetext{
${ }^{\dagger}$ Corresponding Author. E-mail: shryu@khu.ac.kr

\# Present Address: CPRI, Kangwon, Korea
}

disperse CNTs, but their presence simultaneously weakens the mechanical properties of the CNTs. ${ }^{6,7}$ Likewise, chemical functionalization has been widely used to control the interfacial interactions and dispersion of CNTs, but it tends to deteriorate the intrinsic properties of the CNTs. For example, the atomic structural perfection of CNTs can be damaged by the chemical reactions, and the electrical conductivity and mechanical properties of the CNTs can deteriorate as a result. ${ }^{8,9}$ Grafting polymer chains onto the surfaces of CNTs is another well-known method to aid dispersion. ${ }^{2,410}$ These polymer chains can induce homogeneous dispersion of CNTs in the polymer matrix by reducing the tendency of the nanotubes to aggregate. Consequently, the mechanical and electrical properties of composites containing polymer-grafted CNTs are superior to those containing pristine CNTs.

The addition of clay is yet another interesting method to 
improve CNT dispersion since clay is mechanically rigid and has been known to enhance the properties of the resultant polymer composites. Consequently, engaging the synergistic effects of combined nanotubes and nanoclay in order to reinforce epoxy nanocomposites has been suggested as a way to improve CNT properties. Earlier reports revealed that the addition of clay to CNTs significantly improved the debundling of carbon nanotubes, resulting in fine dispersions in polymer matrix ${ }^{11-15}$ Liu et al. showed that the addition of clay significantly enhanced the electrical conductivity of single-walled CNT (SWCNT)/epoxy nanocomposites. ${ }^{11}$ Similarly, Tang found a significant synergistic effect between clay and multi-walled CNTs (MWCNTs) for reinforcing the chitosan matrix. ${ }^{12}$ By incorporating $3 \mathrm{wt} \%$ clay and 0.2-0.6 wt $\%$ CNTs, the tensile strength and Young's modulus of the nanocomposites improved significantly compared with that of neat chitosan. This effect can be explained by the formation of a filler network formed of 1D CNTs and 2D clay platelets combined together. Levchenko et al. studied the influence of organo-clay on the electrical and mechanical properties of PP/MWCNT/organo-clay nanocomposites. ${ }^{13}$ In their study, organo-clay resulted in formation of conductive network containing individual carbon nanotubes, which influenced the mechanisms of charge transport. Furthermore, the addition of organo-clay allowed for a better dispersion of the nanotubes. Lisunova et al. reported that the presence of silane modified the clay in the CNT paste, which improved its uniformity and, as a result, its field emission properties. ${ }^{14}$ They suggested that the addition of organo-clay influenced the deagglomeration of the CNTs in the paste. In their study, organoclay (Closite 30B) and MWCNTs were melt-blended with ethylene vinyl acetate, likely forming a semi-exfoliated/semi-intercalated structure of MMT.

Although the effect of incorporating clay into a CNT/polymer system has been studied, little work has been done to analyze the effect of the clay size on the system. In the present study, clay of various sizes were introduced into SWCNT/epoxy nanocomposites in order to improve the SWCNT dispersion without loss of the electrical conductivity and mechanical properties, while the effect of the clay ball size on these properties were investigated.

\section{EXPERIMENTAL}

\section{Materials}

SWCNTs used in this study were purchased from CNI (USA). Bisphenol-A type low-viscosity epoxy resin (YD-115) was supplied by Kukdo Chemicals Co. (Korea) and an amine-type curing agent (TH-432, Kukdo Chemicals, Korea) was used. Unmodified natural montmorillonite clay (MMT; Cloisite $\mathrm{Na}^{+}$) was obtained from Southern Clay Products Inc.,
USA and the average diameter was $500 \mathrm{~nm}$. Size reduction of MMT was carried out using ball shaker with $500 \mathrm{~g}$ zirconia beads for either 8 or $16 \mathrm{hr}$; the average diameter of the MMTs was then reduced to $250 \mathrm{~nm}$ or $50 \mathrm{~nm}$, respectively. The MMTs were designated as MMT50, MMT25 and MMT05 for $500 \mathrm{~nm}, 250 \mathrm{~nm}$ and $50 \mathrm{~nm}$ MMTs, respectively. The interlayer distance of each MMT was characterized via X-ray and no significant variation was observed following the reduction process.

\section{Preparation of the MMT/SWCNT/epoxy composite}

The epoxy and curing agent were mixed with a $1: 0.6$ weight ratio and the mixture was dissolved in acetone with predetermined amount of SWCNT and MMT. The mixture was then stirred for $1 \mathrm{hr}$ at room temperature using a high-shear mixer (Ultra-Turrax, IKA) at $12000 \mathrm{rpm}$. The mixture was subsequently held under vacuum for $3 \mathrm{hr}$ to remove the acetone and bubbles. Finally, the mixture was poured into a Teflon mold and cured for $2 \mathrm{hr}$ at $120{ }^{\circ} \mathrm{C}$ followed by post curing for $3 \mathrm{hr}$ at $140{ }^{\circ} \mathrm{C}$.

\section{Characterizations}

The particle size of the MMTs was measured using a particle size analyzer (ELS-8000, Potal Otsuka Electronics, Japan). The tensile strength (ASTM D638) and flexural modulus (ASTM D790) were taken with a universal tensile tester (LF plus, Lloyd Instruments Ltd.) at room temperature. The crosshead speed for the tensile and flexural analysis was 3 and $2 \mathrm{~mm} / \mathrm{min}$, respectively. Compression molded specimens were used for these tests. More than three different samples were used and the results were quite reproducible. The surface electrical resistivity of the epoxy nanocomposite film at room temperature was measured via the two probe technique using KEITHLEY 2000 digital multimeter. The surface morphology of the tensile-fractured specimen was investigated using a field emission scanning electron microscope (FE-SEM; LEO SUPRA 55, Carl Zeiss).

\section{Results and Discussion}

Figure 1 shows the effect of MMT50/SWCNT ratio on the surface electrical resistivity of MMT/SWCNT/epoxy composites at various concentrations of SWCNT. Resistivity is decreased with increasing concentration of SWCNT as expected. The addition of MMT50 into SWCNT composite induces further decrease of resistivity and it is strongly dependent on MMT50/SWCNT ratio. The presence of minimum resistivity at certain MMT/SWCNT ratio is observed and the MMT50/ SWCNT ratio for minimum resistivity tends to decrease with 


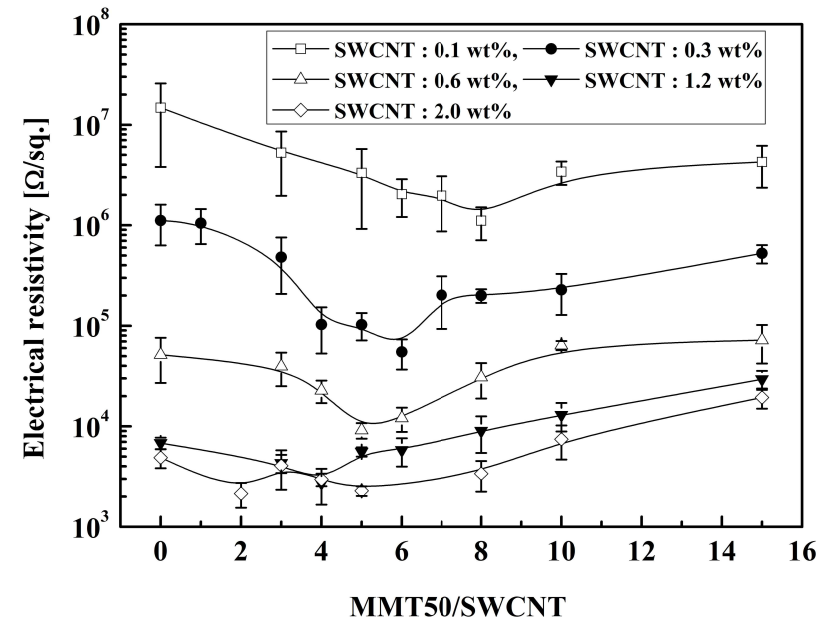

Figure 1. Effect of MMT50/SWCNT ratio on the surface electrical resistivity of MMT/SWCNT/epoxy composites.

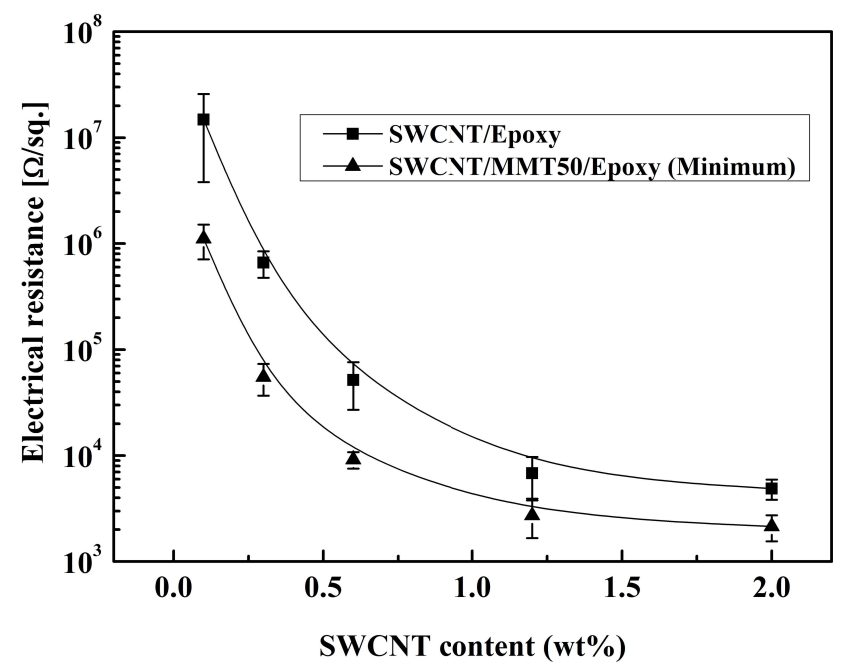

Figure 2. Comparison of surface electrical resistance with various concentration of MMT/SWCNT/epoxy composites at various concentration of SWCNT.

increasing concentration of SWCNT.

Figure 2 clearly shows that resistivity decreases sharply at low concentration of SWCNT and tends to level off above $1.2 \mathrm{wt} \%$ SWCNT irrespective of the presence of the MMT. Minimum resistivity of MMT50/SWCNT/epoxy composites is always lower than that of SWCNT/epoxy composite at same concentration of SWCNT. The decrease of resistivity by the addition of MMT into CNT can be attributed to the improved dispersion of CNTs, while overdose of MMT hinders the electrical conductivity of composite due to the intrinsic insulation characteristic of MMT.

The surface electrical resistivity is also found to be dependent on the size of MMT. Figure 3 shows the surface electrical resistivity for various sizes of MMT. It is clear that the resistivity

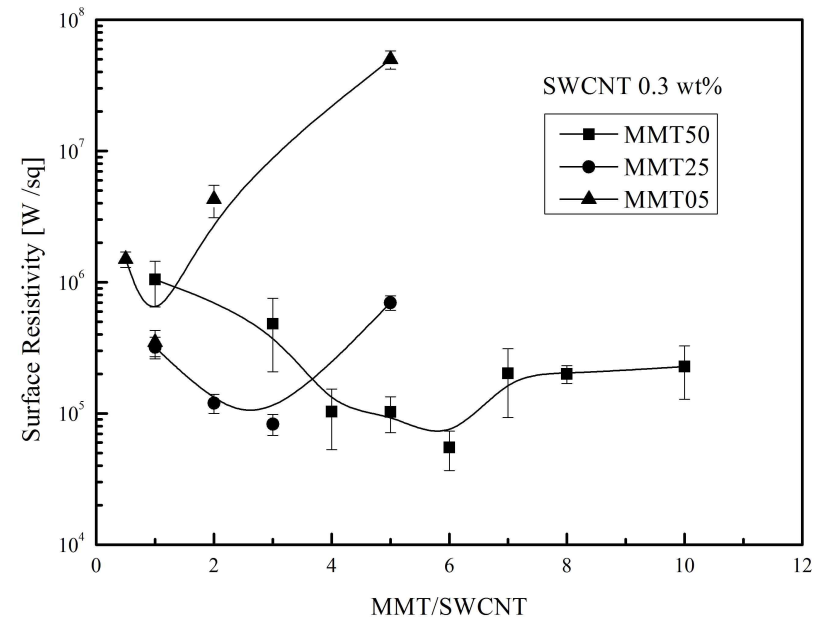

Figure 3. Effect of the size of the MMT on the surface electrical resistivity of the composites.

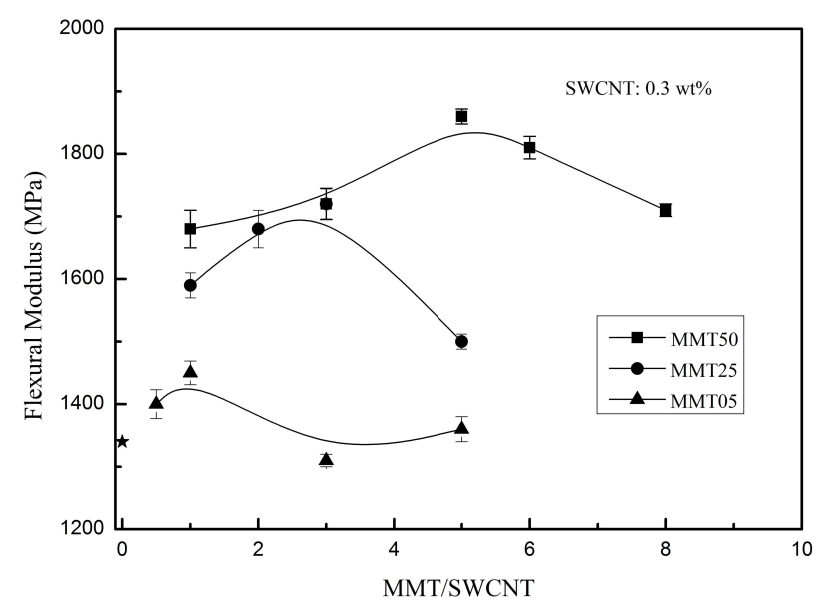

Figure 4. Effect of the size of the MMT on the flexural modulus of the composites.

is dependent on not only the MMT/SWCNT ratio but also the size of MMT. While minimum electrical resistivity of the composites little varied with the MMT size, MMT/SWCNT ratio for minimum resistivity is dependent on the size of MMT. MMT /SWCNT ratio for the lowest resistivity is approximately 6, 3 and 1 for MMT50, MMT25 and MMT05, respectively. The value of minimum resistivity increases with decreasing MMT size. It is also observed that overloading the MMT deteriorates resistivity and it becomes more significant for small MMT.

Figures 4 and 5 show the flexural modulus and tensile strength at break as a function of MMT/SWCNT ratio for the different MMTs with $0.3 \mathrm{wt} \%$ SWCNT. Clearly, the flexural modulus and tensile strength at break are strongly dependent on the MMT/SWCNT ratio as well as the MMT size. These properties tend to increase with the MMT/SWCNT ratio and then decrease after certain ratio has been reached irrespective 


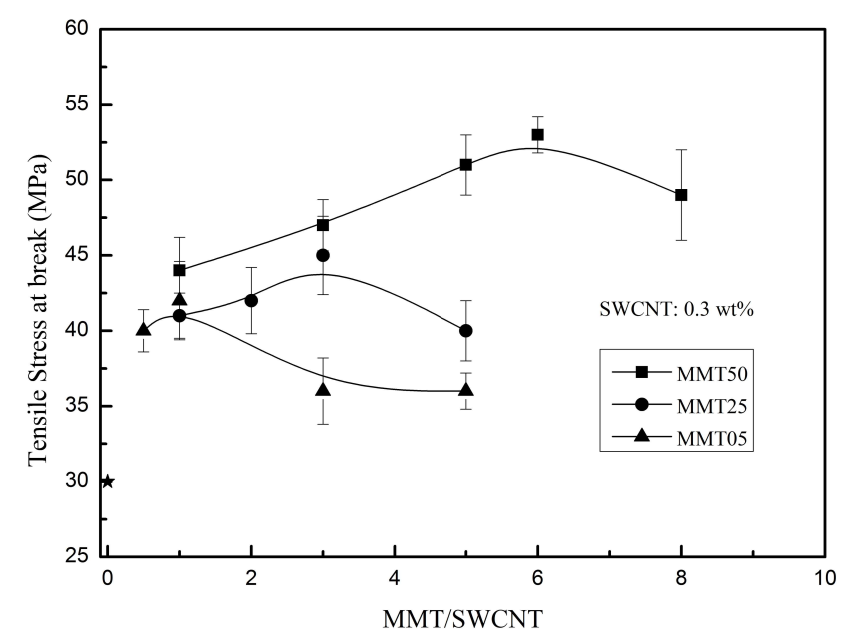

Figure 5. Effect of the size of the MMT on the tensile strength at break of the composites.

of MMT size. MMT/SWCNT ratio for maximum flexural modulus and tensile strength at break decreases with decreasing MMT particle size. The optimum MMT/SWCNT ratio for flexural modulus and tensile strength at break of the MMT50 is 5 6 while it is about 3.0 and 1.0 for MMT25 and MMT05, respectively. Maximum flexural modulus and tensile strength at break at certain MMT/SWCNT ratio decreases with decreasing size of MMT. The relationship between mechanical properties and MMT/SWCNT ratio and size of MMT is shows similar trend as electrical resistivity.

The existence of MMT/SWCNT ratio for maximum mechanical properties or lowest electrical resistivity has been reported previously. Liu et al. found that composites with $2 \mathrm{wt} \%$ MMT showed a higher electrical conductivity than composites without MMT, for up to $0.1 \mathrm{wt} \%$ SWCNT concentration. ${ }^{15}$ At low SWCNT concentrations, however, the conductivity improvement was less clear. For $0.05 \mathrm{wt} \%$ SWCNT, a significant electrical conductivity enhancement was observed with $0.2 \mathrm{wt} \%$ MMT $(\mathrm{MMT} /$ Clay ratio $=4)$, but then decreased slightly with further addition of MMT. This decrease was attributed to the interference within the conductive SWCNT network for high amounts of clay or when the clay concentration had dramatically exceeded that of the SWCNTs. In addition, Tang et al. investigated the synergistic effect of MWCNT/ $\mathrm{Na}^{+}-\mathrm{MMT}$ on the tensile properties of a polymer nanocomposite and observed the maximum tensile strength can be found at an optimum MMT/MWCNT ratio of $3 \mathrm{wt} \%$ MMT to $0.2-0.6 \mathrm{wt} \%$ MWCNT. ${ }^{12}$ Thus, for maximum tensile strength, Tang et al. set their MMT/MWCNT ratio to 15,9 , and 5 for $0.2,0.4$, and $0.6 \mathrm{wt} \%$ of MWCNT, respectively.

The effect of MMT on the CNT/polymer system can be explained through the improved CNT dispersion and formation of a 3D network. ${ }^{12,15} \mathrm{CNTs}$ tend to agglomerate due to strong

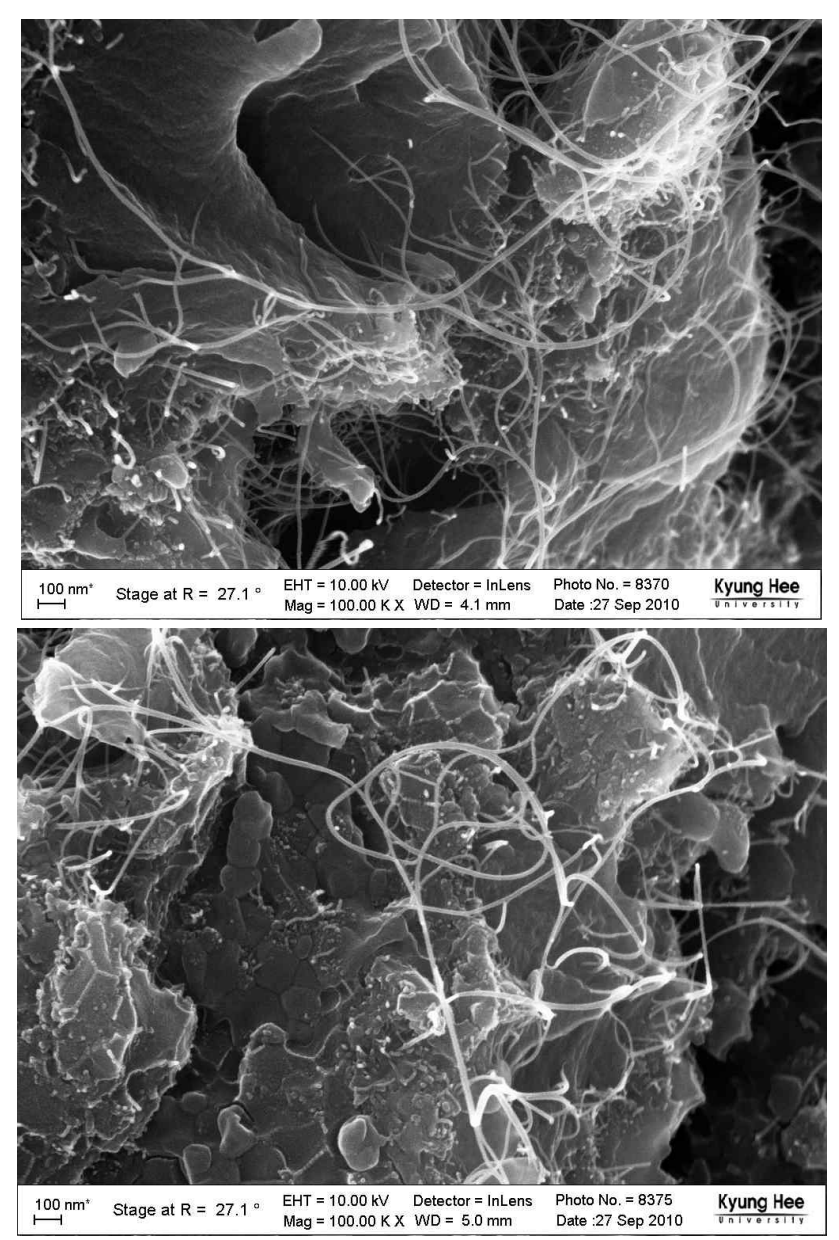

Figure 6. FE-SEM photographs of the tensile-fractured surface of MMT25/SWCNT/epoxy composite ( MMT25/SWCNT ratio for above $=3$ and below $=5$ ).

van der Waals forces, which limit the dispersion of CNTs. Therefore, a suitable amount of stress is needed to break the CNT aggregates. In general, shear and/or elongational stress, which is expressed as a multiplication of the viscosity and the strain rate, is applied to the MMT/SWCNT/epoxy system during the mixing or shaping process. The increased viscosity of the CNT/epoxy system resulting from the addition of MMT induces higher stress and results in more breakage of the SWCNT agglomerates. MMTs can also penetrate into loose CNT agglomerates and it facilitates the separation of the CNTs. Tang et al. proposed formation of 3D clay/CNT networks through the combination of 2D MMTs and 1D CNTs resulted in improved tensile properties. ${ }^{12}$ Liu proposed that the incorporation of MMT increased viscosity, leading to difficulties in migration and reagglomeration. ${ }^{15}$ However, the effect of MMT size has not yet been reported. The effect of MMT size on the optimum MMT/SWCNT ratio for maximum mechanical and minimum electrical properties can be attributed 


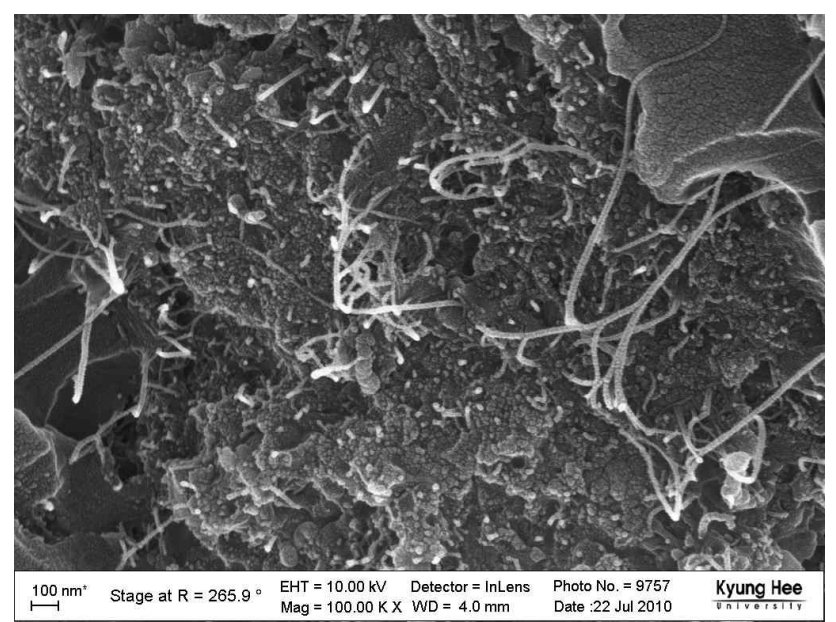

Figure 7. FE-SEM photographs of the tensile-fractured surface with MMT05/SWCNT/epoxy Composite (MMT05/SWCNT ratio $=5)$.

to the different degree of dispersion of MMT and SWCNT. In general, small particles are more difficult to achieve a uniform distribution than large particles. And since the specific volume of MMT increases with decreasing MMT size, smaller MMT will occupy more space for same amount of MMT. This indicates that large number of MMTs between CNTs will present between CNTs and it will hinder the efficient CNT-CNT contacts in the conductive network. This is why MMT/SWCNT ratio for lowest electrical resistivity becomes low for smaller MMT.

Figure 6 shows FE-SEM photographs of the tensile-fractured surface of the MMT25/SWCNT/epoxy composite at $0.3 \mathrm{wt} \%$ SWCNT. Figures 6(a) and (b) represent the photographs for MMT25/SWCNT ratio 3 and 5, respectively. MMT25/SWCNT ratio for lowest resistivity and maximum mechanical properties is 3. It is observed that some portions are not covered with SWCNTs Figure 6(b), while SWCNTs are relatively uniformly distributed on the fractured surface in Figure 6(a). This may explain the poor mechanical and electrical properties for overdose of MMT. Figure 7 represents the MMT05/SWCNT/epoxy composite at a MMT05/SWCNT ratio of 5 and $0.3 \mathrm{wt} \%$ SWCNT. MMT05/SWCNT ratio for lowest resistivity and maximum mechanical properties is 1 , which means that MMT is highly overdosed for Figure 7 specimen. Though the same amount of MMT is added for Figures 6(a) and 7, much less SWCNT is shown on the surface in Figure 7. This is due to the smaller particle size of MMT05, which results in higher volume occupancy between the SWCNTs in the composite. Consequently inferior electrical and mechanical properties of MMT05/SWCNT/epoxy composite are observed compared to that of the MMT25/SWCNT/epoxy composite at a ratio of 3. FE-SEM photographs support the presence of an optimum MMT/SWCNT ratio for the maximum mechanical properties and minimum electrical resistivity.

\section{Conclusions}

$\mathrm{Na}^{+}$-MMT/SWCNT/epoxy nanocomposites were studied in order to investigate the effects of MMT/SWCNT ratio and size of MMT on the mechanical and electrical properties of the composites. Mechanical properties such as tensile strength and the flexural modulus increased with MMT content, reaching a critical level and then tending to decrease with higher concentrations. The surface electrical resistance was found to decrease with increasing MMT content, but tended to increase after the critical content level was reached. Minimum electrical resistance and maximum mechanical properties occurred at same critical MMT/SWCNT ratio for same size of MMT. The critical MMT/SWCNT ratio was strongly dependent on the MMT particle size and decreased with decreasing MMT particle size.

\section{References}

1. Y. Sabba and E. L. Thomas, "High-Concentration Dispersion of Single-Wall Carbon Nanotubes", Macromolecules, 37, 4815 (2004).

2. G. L. Hwang, Y. T. Shieh, and K. C. Hwang, "Efficient load transfer to polymer-grafted multiwalled carbon nanotubes in polymer composites", Adv. Funct. Mater., 14, 487 (2004).

3. M. A. Lopez Manchado, L. Valentini, J. Biagiotti, and J. M. Kenny, "Thermal and mechanical properties of single-walled carbon nanotubes-polypropylene composites prepared by melt processing", Carbon, 43, 1499 (2005).

4. W. S. Choi and S. H. Ryu, "Improvement of interfacial interaction via ATRP in polycarbonate/carbon nanotube nanocomposites", Colloids. Surf. A: Physicochem. Eng. Asp., 375, 55 (2011).

5. M. Lahelin, M. Annala, A. Nykanen, J. Ruokolainen, and J. Seppala, "In situ polymerized nanocomposites: Polystyrene/ CNT and Poly(methyl methacrylate)/CNT composites", Compos. Sci. Technol., 71, 900 (2011).

6. T. Chatterjee, K. Yurekli, V. G. Hadjiev, and R. Krishnamoorti, "Single-walled carbon nanotube dispersions in poly(ethylene oxide)", Adv. Funct. Mater., 15, 1832 (2005).

7. Y. H. Liao, O. Marietta-Tondin, Z. Liang, C. Zhang, and B. Wang, "Investigation of the dispersion process of SWNTs/ SC-15 epoxy resin nanocomposites", Mater. Sci. Eng. A, 385, 175 (2004).

8. J. Chen, R. Ramasubramaniam, C. Xue, and H. Liu, "A versatile, molecular engineering approach to simultaneously enhanced, multifunctional carbon nanotube-polymer composites", Adv. Funct. Mater., 16, 114 (2006).

9. H. Park, J. Zhao, and J. P. Lu, "Effects of sidewall functional- 
ization on conducting properties of single wall carbon nanotubes", Nano Lett., 6, 916 (2006).

10. R. R. Nayak, K. Y. Lee, A. M. Shanmugharaj, and S. H. Ryu, "Synthesis and characterization of styrene grafted carbon nanotube and its polystyrene nanocomposite", Eur. Polym. J., 43, 4916 (2007).

11. M. O. Lisunova, Y. O. Lisunova, S. Lee, J. Kim, K. Joo, and D. Zang, "The influence of organophilic clay on field electron emission uniformity and lifetime of screen printed carbon nanotube film", Thin Solid Films, 518, 279 (2009).

12. C. Tang, L. Xiang, J. Su, K. Wang, C. Yang, Q. Zhang, and Q. Fu, "Largely improved tensile properties of chitosan film via unique synergistic reinforcing effect of carbon nanotube and clay", J. Phys. Chem. B, 112, 3876 (2008).
13. V. Levchenko, Ye. Mamunya, G. Boiteux, M. Lebovka, P. Alcouffe, G. Seytre, and E. Lebedev, "Influence of organo-clay on electrical and mechanical properties of $\mathrm{PP} /$ MWCNT/OC nanocomposites", Eur. Polym. J., 47, 1351 (2011).

14. S. Peterbroeck, M. Alexandre, J. B. Nagy, N. Moreau, A. Destree, F. Monteverde, A. Rulmont, R. Jerome, and Ph. Dubois, "Polymer layered silicate/carbon nanotube nanocomposite: morphological and rheological properties", Macromol. Symp., 221, 115 (2005)

15. L. Liu, J. G. Grunlan, "Assisted dispersion of carbon nanotubes in conductive epoxy nanocomposites", Adv. Funct. Mater., 17, 2343 (2007). 